\title{
Complete arterial grafting for coronary artery disease?
}

Brian F. Buxton, MD

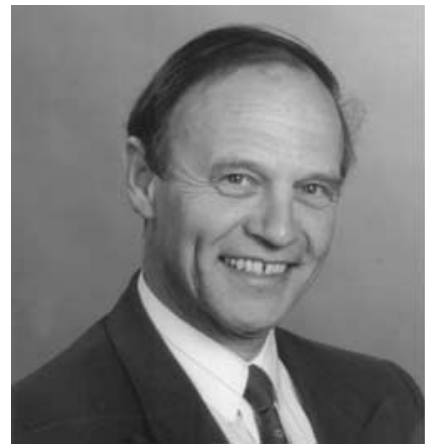

See related article on page 826 .
From the Department of Cardiac Surgery, Austin and Repatriation Medical Centre, Heidelberg, Victoria, Australia.

Received for publication Sept 23, 2002; accepted for publication Oct 21, 2002.

Address for correspondence: Brian F. Buxton, MD, Department of Cardiac Surgery, Austin \& Repatriation Medical Centre, Austin Campus, HSB-5, Studley Rd, Heidelberg, Victoria 3084, Australia.

J Thorac Cardiovasc Surg 2003;125:782-3

Copyright $\odot 2003$ by The American Association for Thoracic Surgery

$0022-5223 / 2003 \$ 30.00+0$

doi:10.1067/mtc. 2003.293

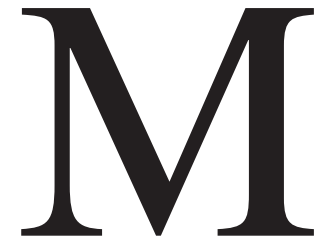

uneretto and colleagues ${ }^{1}$ demonstrated excellent results in patients having total arterial compared with conventional arterial and venous grafting for coronary artery disease in a prospective randomized study. Free arterial grafts are being used increasingly to replace the saphenous vein as a conduit to avoid the late complications of vein graft atherosclerosis. The aim is to prevent major ischemic complications and reoperation. To date, increased complexity, safety, and efficacy concerns have limited the acceptance of extensive or complete arterial grafting. Symptom-directed angiography and late clinical follow-up suggest that the benefits of arterial versus venous grafting have become more obvious with time. Well-constructed and well-conducted prospective randomized controlled trials are therefore very important to define the benefits, if any, and which patients should receive only arterial grafts.

These authors have included a wide range of patients but excluded those with diabetes, obesity, lung disease, and steroids, in whom the risks of sternal ischemia and infection are considered to be high. The information from randomized clinical trials should not be applied universally but rather be confined to similar subsets of patients. In the series by Muneretto and colleagues, ${ }^{1}$ there were few patient exclusions, and therefore these results are relevant to most clinical practices. Semiskeletonization of the internal thoracic artery (ITA) and avoidance of the pleura will minimize chest wall trauma and preserve lung function, thereby increasing the application of the ITA to higher-risk patients. Vein harvesting is often left to junior staff, which might have contributed to the high early failure rate of saphenous vein grafts at 12 months (15\%). The use of a high concentration of papaverine (5 $\mathrm{mmol} / \mathrm{L}$ ) for preparation of radial and right ITAs but not saphenous veins might also have introduced bias. ${ }^{2}$

The authors' algorithm for complete arterial grafting is complex. Their arterial grafting strategy depends primarily on a single arterial inflow through the left ITA by using a radial artery $\mathrm{Y}$ graft in 54\% of patients, thus avoiding right ITA harvesting and aortic manipulation. A dual inflow with a radial artery and left ITA system was used in those patients with a dominant right system (38\%). Where there is doubt about the ability of a Y graft to adequately revascularize the distal branches, a second $\mathrm{Y}$ graft is fashioned with the distal left ITA. The patency of sequential grafts in the presence of a normal inflow will depend on the level of competitive flow in each of the target arteries. Poor patency results have been reported with a radial artery sequential graft to the right coronary artery with a low-grade stenosis. ${ }^{3}$ Many surgeons are reluctant to use a free arterial graft to a native vessel with a stenosis of less than $70 \%$ because of a 3 -fold increased risk of graft failure ${ }^{4}$

Myocardial hypoperfusion remains a theoretical and practical complication when using arterial grafts. Avoidance of hypotension and a low cardiac output in the perioperative period are essential. Graft spasm might be reduced by the use of disease-free arterial conduits, meticulous surgical techniques, topical and (to a lesser extent) systemic vasodilatation with calcium-channel blockade, nitric oxide-cyclic guanosine monophosphate pathway enhancement, and $\alpha$ receptor blockade. ${ }^{5} \mathrm{Al}-$ though there is an adequate flow reserve in a normal left ITA, dependence on a single arterial inflow might pose short-term and long-term ischemic problems if there is proximal disease either in the subclavian artery or ITA or at the level of the $\mathrm{Y}$ anastomosis.

Postoperative angiography was performed in $70 \%$ of the patients in the study by 
Muneretto and colleagues. ${ }^{1}$ The exact numbers of the various grafts were not specified. The authors report a $100 \%$ patency $(n=140)$ of the left ITA to the graft of the left anterior descending artery and a $1.4 \%$ (1/72) failure rate for the radial artery. A string sign developed in $7.5 \%$ (3/40) of right ITAs, and there was an $11 \%$ (15/137) failure rate for the saphenous vein. Most surgeons would regard the string sign as graft failure, thus increasing the total non-left anterior descending arterial graft failure rate to $3.6 \%$. The difference in patency between the arterial venous saphenous grafts remains significant $(P=.04)$. Although the clinical results parallel those of the graft patency, critical analysis of the quality of the end points is essential. Cardiac event-free survival is only useful if the various events are robust. Recurrence of angina is a very weak end point, and nonfatal myocardial infarction requires careful definition. Graft occlusion, reintervention, and death are strong end points on which the trial outcome analyses should depend. The numbers of events that make up the composite end point are not documented. A more meaningful clinical analysis should exclude angina, which would improve the credibility of results but reduce the power of the statistics.

The criteria for accepting the radial artery as a conduit are important. Inadequate ulnar collateral circulation occurs in about $5 \%$ of patients, preventing the use of the radial artery. Disease in the radial artery is more common than in the ITA. ${ }^{6}$ In elderly patients undergoing coronary artery bypass surgery, adaptive fibrointimal hyperplasia, calcification, and atheroma are common pathologic findings in radial arteries. Until the effect of these disease processes on graft function is defined, the use of radial arteries or ITAs with macroscopic disease is probably best avoided.

The findings of Muneretto and colleagues ${ }^{1}$ are important and should be viewed in the context of the Radial Artery Patency Study ${ }^{7}$ and the Radial Artery Patency and Clinical Outcomes 5-year interim results. ${ }^{8}$ The Radial Artery Patency and Clinical Outcomes study confirms that right ITA and radial artery grafts in the non-left anterior descending artery position can be used safely; however, no benefits were detected at 5 years. The Radial Artery Patency Study compares the patency of the saphenous vein with that of the radial artery. A total of 526 patients have been entered in this study, and the early angiographic results will be reported shortly. ${ }^{6}$ The longitudinal follow-up of patients over the next 10 years from these 3 studies will provide surgeons with valuable information about the patency of arterial compared with saphenous vein grafts and the clinical outcomes. Until that time, the hypothesis that total arterial grafting is superior to conventional arterial and venous grafting remains unproven.

\section{References}

1. Muneretto C, Negri A, Manfredi J, et al. Safety and usefulness of composite grafts for total arterial myocardial revascularization: a prospective randomized evaluation. J Thorac Cardiovasc Surg. 2003; 125:826-35.

2. He GW, Rosenfeldt FL, Angus JA. Pharmacological relaxation of the saphenous vein during harvesting for coronary artery bypass grafting. Ann Thorac Surg. 1993;55:1210-7.

3. Maniar H, Sundt T, Barner H, et al. Effect of target stenosis and location on radial artery graft patency. $J$ Thorac Cardiovasc Surg. 2002;1:45-52.

4. Buxton BF, Ruengsakulrach P, Fuller J, Rosalion A, Reid CM, Tatoulis J. The right internal thoracic artery graft-benefits of using pedicled grafts and grafting the left coronary system. Eur J Cardiothorac Surg. 2000;18:255-61.

5. Taggart DP, Dipp M, Mussa S, et al. Phenoxybenzamine prevents spasm in radial artery conduits for coronary artery bypass grafting. J Thorac Cardiovasc Surg. 2000;120:815-7.

6. Ruengsakulrach P, Sinclair R, Komeda M, Raman J, Gordon I, Buxton BF. Comparative histopathology of radial artery versus internal thoracic artery and risk factors for development of intimal hyperplasia and atherosclerosis. Circulation. 1999;100(Suppl 19):II-139-44.

7. The RA Patency Study Investigators. Multicenter Radial Artery Patency Study (RAPS). Study design. Control Clin Trials. 2002;21:397413.

8. Buxton BF, Raman JS, Ruengsakulrach P, et al. Radial artery patency and clinical outcomes: five-year interim results of a randomized trial. $J$ Thorac Cardiovasc Surg. In press. 